\title{
Effects of DNA damage on oocyte meiotic maturation and early embryonic development
}

\author{
Shen YIN, Junyu MA, Wei SHEN (ه) \\ Key Laboratory of Animal Reproduction and Germplasm Enhancement in Universities of Shandong, \\ College of Animal Science and Technology, Qingdao Agricultural University, Qingdao 266109, China
}

\begin{abstract}
DNA damage is one of the most common threats to meiotic cells. It has the potential to induce infertility and genetic abnormalities that may be passed to the embryo. Here, we reviewed exogenous factors which could induce DNA damage. Specially, we addressed the different effects of DNA damage on mouse oocytes and embryonic development. Complex DNA damage, doublestrand breaks, represents a more difficult repair process and involves various repair pathways. Understanding the mechanisms involved in DNA damage responses may improve therapeutic strategies for ovarian cancer and fertility preservation.
\end{abstract}

Keywords DNA damage, double-strand breaks (DSBs), oocyte, embryo

\section{Introduction}

Increasing attention is being paid to how DNA damage influences mammalian oocytes. Women undergoing chemotherapy have an increased expectation of fertility preservation. In 19 European countries where all clinics report to the assisted reproductive technology register, a total of 350143 assisted reproductive cycles were performed in a population of 370 million, representing 947 cycles per million inhabitants [1]. Mammalian oocytes are particularly vulnerable to DNA damage, causing infertility and genetic abnormalities [2,3]. Simple forms of DNA damage such as single-site base damage or singlestrand breaks (SSBs) will be repaired rapidly and easily [4]. However, complex DNA damage, DNA double-strand breaks (DSBs), represent a more difficult process with various repair pathways, which are the major focus of this review. DSBs can be induced by many exogenous or endogenous factors. During development in the fetal ovary, natural recombination can lead to DSBs at early stages of

Received November 27, 2014; accepted December 18, 2014

Correspondence: shenwei427@163.com meiotic prophase I. There are two programmed DNA DSBs which occur during gene rearrangements in immunocytes or during meiotic recombination in germline cells of mammalians [5-8]. Also, DSBs occur in the cleavage stage of embryos, which does not influence the genome sequence because the DSBs can be repaired $[9,10]$. The DSBs are usually sensed and repaired by the DNA damage checkpoint, which can take place during three specific cell cycle stages: $\mathrm{G}_{1} / \mathrm{S}, \mathrm{S}$ and $\mathrm{G}_{2} / \mathrm{M}$ [5]. During mouse oogenesis, the DNA DSBs occur mainly at the pachytene stage in oocytes of the 14-20 days postcoitum fetus [11]. The programmed DSBs of pachytene can be repaired by homologous recombination (HR) when homologous chromosomes form synaptonemal complexes (SC) [12]. However, the abnormal DNA DSBs, if not repaired immediately like the programmed DSBs, could induce chromatin remodeling [13], cell cycle arrest, cell cycle delay, apoptosis or other forms of cell death $[5,14,15]$.

$\mathrm{H} 2 \mathrm{~A}$ histone family member $\mathrm{X}(\mathrm{H} 2 \mathrm{AX})$ is one of several genes coding for histone $\mathrm{H} 2 \mathrm{~A} . \gamma-\mathrm{H} 2 \mathrm{AX}$ is often used as a marker for DNA DSBs damage, because H2AX becomes phosphorylated within 1-3 min after DSBs and forms foci to recruit repairing factors at break sites $[16,17]$. In contrast, poly ADP-ribosepolymerase 1 (PARP-1) is used as a DNA damage repair marker, a sensor of SSBs in DNA and a component of the base excision repair (BER) signaling cascade [18-20]. The typical exogenous factors which can induce DSBs include: chemical drugs, especially cancer chemotherapy, doxorubicin, etoposide [21], bleomycin (BLM) [22]; ionizing radiation (X-rays and $\gamma$ rays), neocarzinostatin [23]; physical treatment, UV-A (wavelength $315-400 \mathrm{~nm}$ in the solar spectrum) [22,24]. The endogenous metabolites or metabolic intermediates produced in response to these factors are reactive oxygen species and products generated as a consequence (e.g., lipid peroxides) [25].

The effect of DNA damage caused by endogenous factors resembles programmed DSBs of pachytene. It is repaired by homologous recombination (HR) when 
homologous chromosomes form synaptonemal complexes (SC) [12]. Next we focused on the DNA damage caused by exogenous factors.

\section{Effects of DNA damage}

\subsection{Chemical drugs}

Bleomycin (BLM) is an antineoplastic drug used widely in clinical applications. DNA DSBs damage will increase with elevated concentration of BLM, observed by the increasing $\gamma$-H2AX signals in mouse oocytes [22]. Germinal vesicle oocytes with DSBs damage induced by BLM can develop into metaphase II stage (MII), with lower germinal vesicle breakdown (GVBD) ratio and longer GVBD period. Also, a delayed polar body extrusion (PBE) can be observed. Once GVBD occurs, however, the PBE will not be affected. There is a higher spindle assembly checkpoint activity during the transition of metaphase I (MI) to anaphase I (AI), indicated by Ccnb1-GFP degradation. Notably, oocytes with DNA DSBs can undergo parthenogenetic activation [22].

Two widely used cancer chemotherapeutic reagents, VP16 and BLM, combined with an in vivo GC-specific DNA topoisomerase II- $\beta$ (TOP2) knockout mouse model are used to investigate the effects of chemotherapy-induced DNA damage on growing mouse follicles [26]. VP-16 can cause massive DSBs in the GCs of growing follicles in a time-dependent manner. This damage, related to apoptotic GC death, results in follicle atresia and ovulation failure [26]. After TOP2 activity is inhibited by a specific inhibitor ICRF-193, an effective decatenation checkpoint does not occur in fully grown oocytes, which undergo the $G_{2} / M$ transition and initiation of meiosis [27]. Also, oocytes treated with ICRF-193 have serious defects in chromosome condensation and homologous chromosome segregation. Furthermore, condensed chromosomes fail to maintain their normal configuration [27].

Etoposide is also a TOP2 inhibitor, which can cause DSBs damage in oocytes even in a low concentration $\left(5 \mu \mathrm{g} \cdot \mathrm{mL}^{-1}\right)$ as in somatic sells [28]. Ataxia telangiectasia mutated (ATM) is a master regulator of the DNA damage response pathway. Mouse oocytes can enter the meiosis phase in the presence of low concentration of etoposide. However, $>80 \%$ of oocytes will arrest at $G_{2} / M$ with higher levels $\left(50-100 \mu \mathrm{g} \cdot \mathrm{mL}^{-1}\right)$ of etoposide, because the ATM-dependent DNA damage checkpoint is activated [21]. Cell division cycle 25 (Cdc25) is essential for meiotic resumption in mouse oocytes. It is the inhibition of $\mathrm{Cdc} 25 \mathrm{~B}$, and not degradation of $\mathrm{Cdc} 25 \mathrm{~A}$, which is responsible for the activation of oocyte DNA damage checkpoint [21].

A novel anticancer agent MLN4924, as a NEDD8activating enzyme E1 (NAE) inhibitor, was identified by high throughput screening. MLN4924 can efficiently inhibit cullin neddylation, which inactivated CRL/SCF E3 ligase to cause substrate accumulation. As a result, a DNA damage response is triggered, cellular apoptosis is induced, and remarkable anticancer effects are observed both in vitro and in vivo [29-31]. MLN4924 activates DNA damage responses and the apoptosis pathways, as shown by the accumulations of $\mathrm{pH} 2 \mathrm{AX}$, pCHK1, pCHK2, cleaved caspase- 3 , and the cyclin-dependent kinase inhibitors p27 and p21 [32].

\subsection{Ionizing radiation}

Oocyte sensitivity to ionizing radiation (IR) varies widely according to the follicle/oocyte stage and the species. The effects of genetic changes depend on the types of initial DNA damage, such as base damage, base loss, SSBs and DSBs. Also, exposure to IR may result in structural chromosome anomalies, including chromosome-type aberrations and chromatid-type aberrations $[4,33]$.

Neocarzinostatin (NCS) is often used as an ionizing radiation mimetic to induce DSBs [34,35]. A lot of $\gamma$ $\mathrm{H} 2 \mathrm{AX}$ foci are associated with chromatin in oocytes followed by NCS treatment. Lower PBE indicates that NCS can inhibit oocyte maturation in a dose dependent manner [23]. This is similar to the somatic cells, in which NCS treatment can inhibit cellular proliferation by $\mathrm{G}_{2}$ cell cycle arrest and induce apoptosis [36].

IR can induce apoptosis of the oocyte in primordial follicles as in somatic cells [37]. Exposure to IR during oogenesis and the diplotene stages of ovarian development can induce the loss of primordial follicles in the postnatal ovary, whereas half of the follicular reserve remains present after irradiation during the zygotene/pachytene stages. This different sensitivity is related to the level of caspase-2 expression [37]. By western blotting and caspase activity analysis, caspase- 2 is activated $2 \mathrm{~h}$ after irradiation. Inhibition of caspase- 2 activity can prevent cleavage of caspase- 9 and partially prevent loss of oocytes in response to irradiation. Therefore, caspase-2-dependent activation of the mitochondrial apoptotic pathway is one mechanism involved in depletion of the primordial follicle pool $[4,37]$.

\subsection{Physical damage}

Laser micro-beam dissection (LMD) can cut the nuclei precisely and effectively, so it is regarded as a physical treatment to induce DNA damage [38,39]. UV-A has been used as a LMD to induce DSBs in germinal vesicle oocytes and zygotes [22,24], as in various kinds of somatic cells [40-42]. LMD can induce DSBs to inhibit or delay $\mathrm{G}_{2} / \mathrm{M}$ transition in oocytes [22]. Chromosome fragmentation cannot affect spindle organization, chromosome segregation and PBE, once GVBD occurs [22]. Also, early embryonic cleavage and development can be disturbed by LMD-induced DSBs damage in the female pronucleus 
[24]. In addition, DNA-damaged blastomeres of 4- or 8cell fail to divide and form compact morulae [24]. Oct4 (a marker of the inner cell mass) and Cdx2 (a marker of trophoblast cells) are expressed normally in the intact blastomere, but not in the DNA damaged blastomere of 2cell embryos. It is possible that the embryos have their own mechanisms to delete DNA-damaged blastomeres, resulting in failure to develop further.

\section{DNA damage repair}

There is much evidence for mammalian oocytes repairing various kinds of DNA damage. The repair occurs either spontaneously or as a consequence of exposure to exogenous factors. Of course, the efficiency of DNA repair varies with different oocyte stages.

Usually, cells respond to DNA damage caused by exogenous and endogenous factors by arresting the cell cycle to allow time for the damage to be repaired. The DNA damage is usually sensed and repaired by the DNA damage checkpoint, which can take place during three specific cell cycle stages: $G_{1} / S, S$ and $G_{2} / M$ [5]. For oocytes that have completed DNA synthesis, the checkpoint operates mainly at meiosis (not strictly regarded as $\mathrm{G}_{2} / \mathrm{M}$ ). Depending on the nature of the DNA damage, it is repaired by a number of different mechanisms during the checkpoint mediated arrest. Simpler forms of DNA damage, such as single sites of base damage or SSBs, will be repaired rapidly and easily by three main pathways, namely base-excision repair, nucleotide excision repair, and mismatch repair [43].

However, DSBs represents a more difficult repair process involving various different repair pathways. DSBs repair is executed by two major mechanisms, nonhomologous end joining (NHEJ) in somatic cells and HR in germline cells $[10,44,45]$. Notably, both NHEJ and HR are functional in zygotes [10]. DSBs are mainly sensed by ATM and ataxia telangiectasia and Rad3-related (ATR) $[46,47]$. The ATM phosphorylates directly or indirectly more than 30 substrates such as the checkpoint kinase 2 (CHK2), DNA-PK and Mre11-complex [48,49]. The activated CHK2 pathway can arrest the cell cycle, followed by the DNA-PK and/or Mre11-complex pathway, which is activated to repair the damaged DNA [49]. After DSBs are repaired, the checkpoint proteins become inactivated to allow the cell cycle progression resume [50].

The damage response is so tightly coordinated that cell cycle resumes as soon as the damage is repaired. However, if the extent of DNA damage could not be repaired completely, programmed mechanisms of cell death become active in order to remove the cells, usually by apoptosis [51,52].

Oocytes contain half of the homologous chromosomes and a minimum amount of cytoplasm after the first meiotic division. Then oocytes enter the second meiotic division without DNA replication and an inter phase. At this stage oocytes are ovulated and fertilization finished. Egg activation triggers the completion of the second meiotic division and initiation of the first embryonic cell cycle. Since the second meiosis is short and without DNA synthesis, there should be one DNA damage repair in meiotic metaphase I before the DNA damage reaches the developing embryo. However, little is known about the possible meiosis DNA damage repair in meiotic metaphase I. It is not known how sensitive the metaphase $I$ is and which factors are involved. Notably, interstrand crosslinks (ICLs) damage caused by mitomycin (MMC) could not inhibit or delay meiotic division in either metaphase I or metaphase II, although the quality and development of preimplantation embryos are influenced [23]. So it is possible that only DSBs damage could establish a meiotic metaphase arrest checkpoint.

The arrest of meiosis caused by DNA DSBs damage is often compared with the arrest at $\mathrm{G}_{2} / \mathrm{M}$ transition in somatic cells. So it is essential to distinguish the molecular mechanisms that govern resumption of meiosis and checkpoint resumption from the $\mathrm{G}_{2}$-arrest induced by DNA damage $[53,54]$. There are many differences between prophase I-arrest in oocytes and $\mathrm{G}_{2}$-arrest in somatic cells. Plk1 is the principle target for Cdc14B-APC/Cdh1 in somatic cells [55], whereas CCNB1 is the primary target in mouse oocytes [56,57]. Plk1 is essential for $\mathrm{G}_{2}$-checkpoint recovery [58], but dispensable for resumption of meiosis, even enhancing the process [53]. DSBs, prior to entry into mitosis, activate a $\mathrm{G}_{2}$-checkpoint that delays initiation of mitosis in the presence of damaged DNA. ATM is also required for the DNA lesions in oocytes, including natural DSBs at early stages of prophase I during the fetal ovary development, and unnatural DSBs damage caused by exogenous factors, such as UV and drugs. Female mice with absence of ATM are completely infertile due to meiotic problems at prophase I as a response to damaged DSBs $[59,60]$. Meiotic DSBs are initiated by Spo11via a transesterification reaction. Oocytes from Spo11-deficient mice exhibit prophase I arrest and die during postnatal development [60]. These findings suggest that normal oocyte maturation and reproduction are closely connected with DSBs and DNA repair [61]. Both oocytes arrested at prophase I and somatic cells arrested at $\mathrm{G}_{2}$ must resume the cell cycle at an appropriate time for future development.

Somatic cells arrested at $\mathrm{G}_{2}$ depend on the action of Cdc14B and APC-Cdh1, both of which are also essential for the prophase I arrest of mouse oocytes [56,57]. Notably, Cdc14B is sequestered in the nucleus in normal somatic cells not suffering DNA damage, and leaves the nucleus following DNA damage [55]. In oocytes arrested in prophase I, Cdc14B does not localize in the nucleus, which suggests that it may be active [57]. After DNA damage, the resumption of somatic cell cycle requires Plk1 and Cdc25B [62], both of which are required for normal mitotic entry $[62,63]$, whereas resumption of meiosis only 
requires $\mathrm{Cdc} 25 \mathrm{~B}$ [62]. In addition, protein phosphatase 1 (PP1) and protein phosphatase 2A (PP2A) are also involved in resumption of meiosis and $\mathrm{G}_{2}$-checkpoint recovery. Okadaic acid (OA), a PP1 and PP2A inhibitor, can induce resumption of meiosis of oocytes cultured with a PDE inhibitor [64-66]. Also, OA can override the $\mathrm{G}_{2^{-}}$ checkpoint and induce premature mitotic entry in human cancer cells [67] and in HeLa cells independent of Cdk1 activity [68].

Oocyte maturation and embryonic development is sensitive to DNA damage. Substantial evidence now exists to concerning the DNA damage checkpoint by which the mammalian oocyte responds to DNA damage. However, unlike mitosis, cell cycle arrest is absent in M-phase or in the early embryos when DNA damage occurs. So the DNA damage in meiosis is very different. Why is the DNA damage checkpoint not activated in fully grown oocytes? What mechanisms are recruited in meiosis to repair DNA damage? Thus there are still many puzzles involved in the DNA damage and repair of mammalian oocytes.

Acknowledgements This study was supported by the National Natural Science Foundation of China (31171376 and 31401276), National Basic Research Program of China (2012CB944401).

Compliance with ethics guidelines Shen Yin, Junyu Ma and Wei Shen declare that they have no conflict of interest or financial conflicts to disclose.

This article is a review and does not contain any studies with human or animal subjects performed by any of the authors.

\section{References}

1. Ferraretti A P, Goossens V, de Mouzon J, Bhattacharya S, Castilla J A, Korsak V, Kupka M, Nygren K G, Nyboe Andersen A. Assisted reproductive technology in Europe, 2008: results generated from European registers by ESHRE. Human Reproduction, 2012, 27(9): 2571-2584

2. Jacquet P, Adriaens I, Buset J, Neefs M, Vankerkom J. Cytogenetic studies in mouse oocytes irradiated in vitro at different stages of maturation, by use of an early preantral follicle culture system. Mutation Research, 2005, 583(2): 168-177

3. Tease C. X-ray-induced chromosome aberrations in dictyate oocytes of young and old female mice. Mutation Research, 1983, 119(2): 191-194

4. Adriaens I, Smitz J, Jacquet P. The current knowledge on radio sensitivity of ovarian follicle development stages. Human Reproduction Update, 2009, 15(3): 359-377

5. Dasika G K, Lin S C, Zhao S, Sung P, Tomkinson A, Lee E Y. DNA damage-induced cell cycle checkpoints and DNA strand break repair in development and tumorigenesis. Oncogene, 1999, 18(55): 7883-7899

6. Roig I, Liebe B, Egozcue J, Cabero L, Garcia M, Scherthan H. Female-specific features of recombinational double-stranded DNA repair in relation to synapsis and telomere dynamics in human oocytes. Chromosoma, 2004, 113(1): 22-33

7. Grey C, Baudat F, de Massy B. Genome-wide control of the distribution of meiotic recombination. PLoS Biology, 2009, 7(2): e35

8. Cheng E Y, Hunt P A, Naluai-Cecchini T A, Fligner C L, Fujimoto V Y, Pasternack T L, Schwartz J M, Steinauer J E, Woodruff T J, Cherry S M, Hansen T A, Vallente R U, Broman K W, Hassold T J. Meiotic recombination in human oocytes. PLOS Genetics, 2009, 5 (9): e1000661

9. Lambert J, Hergenröder R, Suter D, Deckert V. Probing liquidliquid interfaces with spatially resolved NMR spectroscopy. Angewandte Chemie, 2009, 48(34): 6343-6345

10. Derijck A, van der Heijden G, Giele M, Philippens M, de Boer P. DNA double-strand break repair in parental chromatin of mouse zygotes, the first cell cycle as an origin of de novo mutation. Human Molecular Genetics, 2008, 17(13): 1922-1937

11. Speed R M. Meiosis in the foetal mouse ovary: I. An analysis at the light microscope level using surface-spreading. Chromosoma, 1982, 85(3): 427-437

12. Speed R M, Chandley A C. Meiosis in the foetal mouse ovary: II. Oocyte development and age-related aneuploidy. Does a production line exist? Chromosoma, 1983, 88(3): 184-189

13. Pandita T K, Richardson C. Chromatin remodeling finds its place in the DNA double-strand break response. Nucleic Acids Research, 2009, 37(5): 1363-1377

14. van Gent D C, Hoeijmakers J H, Kanaar R. Chromosomal stability and the DNA double-stranded break connection. Nature Reviews Genetics, 2001, 2(3): 196-206

15. Bohgaki T, Bohgaki M, Hakem R. DNA double-strand break signaling and human disorders. Genome Integrity, 2010, 1: 15

16. Paull T T, Rogakou E P, Yamazaki V, Kirchgessner C U, Gellert M, Bonner W M. A critical role for histone $\mathrm{H} 2 \mathrm{AX}$ in recruitment of repair factors to nuclear foci after DNA damage. Current Biology, 2000, 10(15): 886-895

17. Rogakou E P, Pilch D R, Orr A H, Ivanova V S, Bonner W M. DNA double-stranded breaks induce histone H2AX phosphorylation on serine 139. Journal of Biological Chemistry, 1998, 273(10): 58585868

18. Durkacz B W, Omidiji O, Gray D A, Shall S. (ADP-ribose) participates in DNA excision repair. Nature, 1980, 283(5747): 593596

19. Malanga M, Althaus F R. The role of poly(ADP-ribose) in the DNA damage signaling network. Biochemistry and Cell Biology, 2005, 83 (3): 354-364

20. Godon C, Cordelières F P, Biard D, Giocanti N, Mégnin-Chanet F, Hall J, Favaudon V. PARP inhibition versus PARP-1 silencing: different outcomes in terms of single-strand break repair and radiation susceptibility. Nucleic Acids Research, 2008, 36(13): 4454-4464

21. Marangos P, Carroll J. Oocytes progress beyond prophase in the presence of DNA damage. Current Biology, 2012, 22(11): 989-994

22. Ma J Y, Ou Yang Y C, Wang Z W, Wang Z B, Jiang Z Z, Luo S M, Hou Y, Liu Z H, Schatten H, Sun Q Y. The effects of DNA doublestrand breaks on mouse oocyte meiotic maturation. Cell Cycle, 2013, 12(8): 1233-1241

23. Yuen W S, Merriman J A, O’Bryan M K, Jones K T. DNA double strand breaks but not interstrand crosslinks prevent progress through meiosis in fully grown mouse oocytes. PLoS ONE, 2012, 7(8): 
e43875

24. Wang Z W, Ma X S, Ma J Y, Luo Y B, Lin F, Wang Z B, Fan H Y, Schatten H, Sun Q Y. Laser microbeam-induced DNA damage inhibits cell division in fertilized eggs and early embryos. Cell Cycle, 2013, 12(20): 3336-3344

25. De Bont R, van Larebeke N. Endogenous DNA damage in humans: a review of quantitative data. Mutagenesis, 2004, 19(3): 169-185

26. Zhang Y L, Yu C, Ji S Y, Li X M, Zhang Y P, Zhang D, Zhou D, Fan $\mathrm{H}$ Y. TOP2 $\beta$ is essential for ovarian follicles that are hypersensitive to chemotherapeutic drugs. Molecular Endocrinology, 2013, 27 (10): 1678-1691

27. Li X M, Yu C, Wang Z W, Zhang Y L, Liu X M, Zhou D, Sun Q Y, Fan H Y. DNA topoisomerase II is dispensable for oocyte meiotic resumption but is essential for meiotic chromosome condensation and separation in mice. Biology of Reproduction, 2013, 89(5): 118

28. Wu C C, Li T K, Farh L, Lin L Y, Lin T S, Yu Y J, Yen T J, Chiang C W, Chan N L. Structural basis of type II topoisomerase inhibition by the anticancer drug etoposide. Science, 2011, 333(6041): 459-462

29. Jia L, Li H, Sun Y. Induction of p21-dependent senescence by an NAE inhibitor, MLN4924, as a mechanism of growth suppression. Neoplasia, 2011, 13(6): 561-569

30. Luo Z, Pan Y, Jeong L S, Liu J, Jia L. Inactivation of the Cullin (CUL)-RING E3 ligase by the NEDD8-activating enzyme inhibitor MLN4924 triggers protective autophagy in cancer cells. Autophagy, 2012, 8(11): 1677-1679

31. Luo Z, Yu G, Lee H W, Li L, Wang L, Yang D, Pan Y, Ding C, Qian J, Wu L, Chu Y, Yi J, Wang X, Sun Y, Jeong L S, Liu J, Jia L. The Nedd8-activating enzyme inhibitor MLN4924 induces autophagy and apoptosis to suppress liver cancer cell growth. Cancer Research, 2012, 72(13): 3360-3371

32. Pan W W, Zhou J J, Yu C, Xu Y, Guo L J, Zhang H Y, Zhou D, Song F Z, Fan H Y. Ubiquitin E3 ligase CRL4 (CDT2/DCAF2) as a potential chemotherapeutic target for ovarian surface epithelial cancer. Journal of Biological Chemistry, 2013, 288(41): 2968029691

33. Savage J R. A brief survey of aberration origin theories. Mutation Research, 1998, 404(1-2): 139-147

34. Beerman T A, Goldberg I H. The relationship between DNA strandscission and DNA synthesis inhibition in HeLa cells treated with neocarzinostatin. Biochimica et Biophysica Acta (BBA) - Nucleic Acids and Protein Synthesis, 1977, 475(2): 281-293

35. Hatayama T, Goldberg I H. DNA damage and repair in relation to cell killing in neocarzinostatin-treated HeLa cells. Biochimica et Biophysica Acta (BBA) - Nucleic Acids and Protein Synthesis, 1979, 563(1): 59-71

36. Bañuelos A, Reyes E, Ocadiz R, Alvarez E, Moreno M, Monroy A, Gariglio P. Neocarzinostatin induces an effective p53-dependent response in human papillomavirus-positive cervical cancer cells. The Journal of Pharmacology and Experimental Therapeutics, 2003, 306(2): 671-680

37. Hanoux V, Pairault C, Bakalska M, Habert R, Livera G. Caspase-2 involvement during ionizing radiation-induced oocyte death in the mouse ovary. Cell Death and Differentiation, 2007, 14(4): 671681

38. Lukas C, Falck J, Bartkova J, Bartek J, Lukas J. Distinct spatiotemporal dynamics of mammalian checkpoint regulators induced by DNA damage. Nature Cell Biology, 2003, 5(3): 255-260

39. Jazayeri A, Falck J, Lukas C, Bartek J, Smith G C, Lukas J, Jackson S P. ATM- and cell cycle-dependent regulation of ATR in response to DNA double-strand breaks. Nature Cell Biology, 2006, 8(1): 3745

40. Botchway S W, Reynolds P, Parker A W, O’Neill P. Use of near infrared femtosecond lasers as sub-micron radiation microbeam for cell DNA damage and repair studies. Mutation Research, 2010, 704 (1-3): 38-44

41. Bekker-Jensen S, Lukas C, Kitagawa R, Melander F, Kastan M B, Bartek J, Lukas J. Spatial organization of the mammalian genome surveillance machinery in response to DNA strand breaks. The Journal of Cell Biology, 2006, 173(2): 195-206

42. Rogakou E P, Boon C, Redon C, Bonner W M. Megabase chromatin domains involved in DNA double-strand breaks in vivo. The Journal of Cell Biology, 1999, 146(5): 905-916

43. Carroll J, Marangos P. The DNA damage response in mammalian oocytes. Frontiers in Genetics, 2013, 4: 117

44. Aguilera A, Gómez-González B. Genome instability: a mechanistic view of its causes and consequences. Nature Reviews Genetics, 2008, 9(3): 204-217

45. Cohn M A, D'Andrea A D. Chromatin recruitment of DNA repair proteins: lessons from the fanconi anemia and double-strand break repair pathways. Molecular Cell, 2008, 32(3): 306-312

46. Reinhardt H C, Yaffe M B. Kinases that control the cell cycle in response to DNA damage: Chk1, Chk2, and MK2. Current Opinion in Cell Biology, 2009, 21(2): 245-255

47. Smith J, Tho L M, Xu N, Gillespie D A. The ATM-Chk2 and ATRChk1 pathways in DNA damage signaling and cancer. Advances in Cancer Research, 2010, 108: 73-112

48. Lavin M F, Delia D, Chessa L. ATM and the DNA damage response: workshop on ataxia-telangiectasia and related syndromes. EMBO Reports, 2006, 7(2): 154-160

49. Shiloh Y. The ATM-mediated DNA-damage response: taking shape. Trends in Biochemical Sciences, 2006, 31(7): 402-410

50. Branzei D, Foiani M. Regulation of DNA repair throughout the cell cycle. Nature Reviews Molecular Cell Biology, 2008, 9(4): 297-308

51. Bartek J, Lukas J. DNA damage checkpoints: from initiation to recovery or adaptation. Current Opinion in Cell Biology, 2007, 19 (2): 238-245

52. Ciccia A, Elledge S J. The DNA damage response: making it safe to play with knives. Molecular Cell, 2010, 40(2): 179-204

53. Solc P, Schultz R M, Motlik J. Prophase I arrest and progression to metaphase I in mouse oocytes: comparison of resumption of meiosis and recovery from $\mathrm{G}_{2}$-arrest in somatic cells. Molecular Human Reproduction, 2010, 16(9): 654-664

54. Lindqvist A, Rodríguez-Bravo V, Medema R H. The decision to enter mitosis: feedback and redundancy in the mitotic entry network. The Journal of Cell Biology, 2009, 185(2): 193-202

55. Bassermann F, Frescas D, Guardavaccaro D, Busino L, Peschiaroli A, Pagano M. The Cdc14B-Cdh1-Plk1 axis controls the $\mathrm{G}_{2}$ DNAdamage-response checkpoint. Cell, 2008, 134(2): 256-267

56. Reis A, Chang H Y, Levasseur M, Jones K T. APCcdh1 activity in mouse oocytes prevents entry into the first meiotic division. Nature Cell Biology, 2006, 8(5): 539-540

57. Schneider M R, Wolf E. The epidermal growth factor receptor 
ligands at a glance. Journal of Cellular Physiology, 2009, 218(3): 460-466

58. Macůrek L, Lindqvist A, Lim D, Lampson M A, Klompmaker R, Freire R, Clouin C, Taylor S S, Yaffe M B, Medema R H. Polo-like kinase-1 is activated by aurora A to promote checkpoint recovery. Nature, 2008, 455(7209): 119-123

59. Barlow C, Liyanage M, Moens P B, Tarsounas M, Nagashima K, Brown K, Rottinghaus S, Jackson S P, Tagle D, Ried T, WynshawBoris A. Atm deficiency results in severe meiotic disruption as early as leptonema of prophase I. Development, 1998, 125(20): 40074017

60. Di Giacomo M, Barchi M, Baudat F, Edelmann W, Keeney S, Jasin M. Distinct DNA-damage-dependent and-independent responses drive the loss of oocytes in recombination-defective mouse mutants. Proceedings of the National Academy of Sciences of the United States of America, 2005, 102(3): 737-742

61. Jackson S P, Bartek J. The DNA-damage response in human biology and disease. Nature, 2009, 461(7267): 1071-1078

62. Lincoln A J, Wickramasinghe D, Stein P, Schultz R M, Palko M E, De Miguel M P, Tessarollo L, Donovan P J. Cdc25b phosphatase is required for resumption of meiosis during oocyte maturation. Nature Genetics, 2002, 30(4): 446-449
63. Lindqvist A, Källström H, Lundgren A, Barsoum E, Rosenthal C K. $\mathrm{Cdc} 25 \mathrm{~B}$ cooperates with $\mathrm{Cdc} 25 \mathrm{~A}$ to induce mitosis but has a unique role in activating cyclin B1-Cdk1 at the centrosome. The Journal of Cell Biology, 2005, 171(1): 35-45

64. Alexandre H, Van Cauwenberge A, Tsukitani Y, Mulnard J. Pleiotropic effect of okadaic acid on maturing mouse oocytes. Development, 1991, 112(4): 971-980

65. Gavin A C, Tsukitani Y, Schorderet-Slatkine S. Induction of Mphase entry of prophase-blocked mouse oocytes through microinjection of okadaic acid, a specific phosphatase inhibitor. Experimental Cell Research, 1991, 192(1): 75-81

66. Schwartz D A, Schultz R M. Stimulatory effect of okadaic acid, an inhibitor of protein phosphatases, on nuclear envelope breakdown and protein phosphorylation in mouse oocytes and one-cell embryos. Developmental Biology, 1991, 145(1): 119-127

67. Ghosh S, Schroeter D, Paweletz N. Okadaic acid overrides the Sphase check point and accelerates progression of $\mathrm{G}_{2}$-phase to induce premature mitosis in HeLa cells. Experimental Cell Research, 1996, 227(1): 165-169

68. Ghosh S, Paweletz N, Schroeter D. Cdc2-independent induction of premature mitosis by okadaic acid in HeLa cells. Experimental Cell Research, 1998, 242(1): 1-9 